\title{
PROFESSORAS MORALIZADORAS,
} NORMALIZADORAS OU AUSENTES -

\section{A LITERATURA INFANTIL RETRATANDO}

\section{AS DIFERENÇAS}

\author{
Edgar Roberto Kirchof \\ Professor do Curso de Letras e do \\ Programa de Pós-Graduação em Educação - ULB \\ Rosa Maria Hessel Silveira \\ Professora do Curso de Pedagogia e do \\ Programa de Pós-Graduação em Educação - ULB
}

Resumo: Em face da proliferação, no Brasil, nos últimos anos, de livros voltados ao público infantil cuja principal temática é a questão da diferença, o presente artigo propõe uma reflexão sobre a maneira como diferenças ligadas a grupos minoritários e a gênero são representadas em livros infantis. As análises centram-se nos papéis desempenhados pela personagem-professora ao ser confrontada com a diferença e são realizadas a partir de 10 livros publicados no Brasil, entre 2004 e 2008, por autores e editoras diferentes. O principal argumento defendido é que o interesse crescente por esse tema, em livros infantis, nas últimas décadas, deve-se, de um lado, a várias políticas governamentais de inclusão social, implementadas nos últimos anos, e, de outro lado, ao trabalho da crítica e da produção literária em âmbito internacional, que, desde a década de 70 do século XX, vem denunciando estereótipos em relação a grupos minoritários.

Palavras-chave: Representação; Diferença; Literatura Infantil; Gênero; Grupos Minoritários.

Abstract: Due to a increase of children's fiction addressing the subject of 'differences' in the last few years in the Brazilian context, this study proposes a reflection on the way these books represent differences related to minority groups and gender. The analyses are focused on the character roles that are played by the teacher as she/he is faced with differences. Ten books published in Brazil by different authors and publishing houses between 2004 and 2008 were analyzed. The main argument of the analyses is based on the assumption that the increase of the issue of 'difference' in recent Brazilian children's books is in accordance with various state policies relating to minorities rights, on the one hand, and to a broad development of criticism of children's fiction from the 1970s until the present day as to stereotypical representation of gender and minority groups in the British and North-American context, on the other hand.

Keywords: Representation; Difference; Children's Literature; Gender; Minority Groups. 
O argumento principal do presente $\operatorname{artigo~}^{1}$ é que as representações ou imagens de infância que acompanham e sustentam a literatura infantil, ao longo de seu percurso histórico, estão estreitamente vinculadas ao modo como ela se articula aos demais campos da cultura com os quais mantém relações de interdependência. Nesse contexto, pretendemos argumentar que, no Brasil, em especial na última década, o interesse expressivo por temas ligados às diferenças - como gênero, etnia, orientação sexual, deficiência física, enfim, grupos minoritários -, perceptível em uma gama considerável de livros produzidos para a infância, situa-se no contexto de discussões que afloraram no tecido social, tendo repercutido inclusive na promoção de várias políticas governamentais de inclusão social e escolar da diferença.

Além disso, também pretendemos argumentar que o aumento significativo da representação da diferença, na literatura recente destinada a crianças brasileiras, pode ser vinculado com o contexto mais amplo da crítica e da produção literária em âmbito internacional. Desde a década de 70, tem havido, principalmente no contexto britânico e norte-americano, um trabalho de crítica voltado para a literatura infantil cujo principal objetivo tem sido a denúncia e a desconstrução de representações estereotipadas de minorias em livros infantis, o que gerou não apenas debates calorosos mas também novas políticas de produção literária no âmbito europeu e internacional. Tais políticas repercutem de diferentes modos no contexto brasileiro, destacando-se o aumento de traduções de livros marcados por essa temática, destinados a crianças, pelas grandes editoras brasileiras, um fenômeno que ainda não completa dez anos.

O artigo apresenta, inicialmente, um panorama histórico muito breve da literatura infantil, enfatizando sua interdependência com relação a outros campos da cultura: sua ligação com a instituição familiar, a escola, o Estado e, principalmente, a crítica literária realizada a partir dos anos 60 do século XX. Em seguida, a fim de demonstrar de que maneira as representações da diferença na infância estão marcadas por políticas de inclusão, serão analisados 10 livros de autores (brasileiros e estrangeiros) e editoras distintas, voltados para leitores dos anos iniciais de escolaridade, publicados recentemente no Brasil, entre os anos 2004 e 2008.

\footnotetext{
${ }^{1}$ O presente artigo integra o Projeto de Pesquisa "Narrativas, diferenças e infância contemporânea", com apoio do CNPq (auxílio e bolsas: de Produtividade em Pesquisa e PIBIC-CNPq), assim como da ULBRA-RS (bolsa de Iniciação Científica), em desenvolvimento no PPGEdu-ULBRA,RS.
} 
As análises estarão centradas nos modos como a personagem professora (eventualmente, professor) é construída e representada quando é confrontada com a temática da diferença, sendo que os livros escolhidos para análise focalizam diferenças de natureza variada. Há dois livros sobre o tema etnia (especificamente, a negritude); um sobre deficiência visual; um sobre gênero; um sobre a diferença relacionada à Síndrome de Down; um acerca da hiperatividade; um sobre o nanismo; um sobre a tetraplegia; dois abordam a diferença de modo simbólico ou alegórico. Observe-se, entretanto, que o imperativo da abordagem da diferença, nessas obras, é tamanho que, por vezes, mais de uma diferença é ressaltada em um só livro, tanto no texto escrito quanto no texto imagético, ou através de ambos.

\section{O campo da literatura infantil}

Em uma análise entrementes antológica da obra de Flaubert ${ }^{2}$, o sociólogo francês Pierre Bourdieu afirma que se deve a Michel Foucault a formulação mais rigorosa dos fundamentos que regem as relações de interdependência que dão origem a todas as obras culturais. Em poucos termos, para Bourdieu, Foucault possui o mérito de nos ter alertado que "nenhuma obra cultural existe por si mesma, isto é, fora das relações de interdependência que a unem a outras obras" (BOURDIEU, 1996, p. 225).

Em seu próprio trabalho, Bourdieu procura compreender os espaços da produção cultural enquanto campos. Não se trata de postular a existência de um Zeitgeist ou de um espírito de época coerente, cuja ideologia estaria presente em todas as manifestações culturais produzidas em determinado período. Antes, Bourdieu propõe reconhecer que cada campo cultural específico - como a música, a pintura, a literatura, por exemplo -, ao mesmo tempo em que possui uma história autônoma, também está inserido em vários outros contextos socioculturais, que podem corresponder a outros campos de criação cultural ou a campos de fundo político e econômico. As relações entre tais campos são sempre marcadas por lutas de poder, visando sua conservação ou transformação. Em breves termos, os objetos culturais inserem-se em um contexto amplo de posições ocupadas por agentes e instituições na estrutura de cada campo específico, cujo poder e reconhecimento é sempre negociado (id., ibid., p. 235).

\footnotetext{
${ }^{2}$ BOURDIEU, Pierre. As regras da arte: gênese e estrutura do campo literário. São Paulo: Companhia das Letras, 1996.
} 
O campo específico da assim chamada literatura infantil se constituiu, no mundo ocidental, articulado ao próprio desenvolvimento da noção de infância, apontado, entre outros, por Ariès, em livro já clássico ${ }^{3}$, ainda que sujeito a críticas variadas. Para Shavit (2003, p. 23), a nova interpretação da infância que emerge no início do século XVII, na Europa ocidental, provocou o surgimento de "duas novas instituições culturais: um novo sistema de educação, o sistema escolar, e uma nova prática de leitura, que produziu o surgimento da idéia de infância como infantil." Assim sendo, é possível afirmar que os primeiros livros de literatura dirigidos intencionalmente para crianças foram produzidos no final do século XVII e durante todo o século XVIII, motivados por dois principais fatores históricos. O primeiro deles é a reconfiguração do modelo familiar, que passa de uma estrutura mais ampla de relações de parentesco - predominante na Idade Média para uma estrutura unicelular, predominante na sociedade burguesa. Já o segundo fator determinante para o surgimento do campo da literatura infantil é a reconfiguração da leitura a partir do espaço escolar. Antes da instituição do modelo familiar burguês, não havia uma concepção especial de infância e, portanto, não havia a necessidade de uma instituição escolar nos moldes que passa a preencher a partir de então. Conforme Zilberman (1998, p. 13), “a nova valorização da infância gerou maior união familiar, mas igualmente meios de controle do desenvolvimento intelectual da criança e manipulação de suas emoções. Literatura infantil e escola, inventada a primeira e reformada a segunda, são convocadas para cumprir essa missão”. Como se percebe, a própria emergência da literatura infantil enquanto um campo específico da cultura ocidental ocorre numa relação de interdependência com as instituições da família burguesa e da escola moderna.

Por essa razão, desde o seu surgimento, na Europa, a literatura para crianças vem, de certa forma, correspondendo a diferentes imagens ou representações de infância. Devido ao seu forte vínculo com a família burguesa e com a escola, ainda no século XVIII, segundo Shavit (2003, p. 26), predominaram duas principais representações do infantil: o entendimento da infância como um repositório de ingenuidade, inocência, candura e graça, como fonte de divertimento e alegria, de um lado; a noção segundo a qual as crianças deveriam ser educadas e disciplinadas, de outro. Como se percebe, a primeira concepção está mais ligada aos valores da família

\footnotetext{
${ }^{3}$ ARIES, Philippe. História social da criança e da família. Rio de Janeiro: Zahar, 1978.
} 
burguesa, ao passo que a segunda vincula-se mais fortemente ao intuito pedagogizante e moralizante do espaço escolar.

Assim sendo, não surpreende o fato de que a maior parte dos livros dedicados a crianças, desde o século XVIII até o século XIX, tenha sido marcada por um forte caráter didático e pedagógico, destinado à promoção de valores morais, sendo que a maioria desses textos, principalmente no século XVIII, foi produzida por pedagogos e professores.

\section{A crítica literária: denunciando estereótipos de gênero e de grupos minoritários}

Devido a essa conexão tão íntima com a escola e com valores explicitamente moralizantes e utilitários, desde os seus primórdios a literatura infantil tem sido considerada uma espécie de "colônia da pedagogia", para utilizar uma expressão de Zilberman (1998, p. 13), o que lhe tem conferido, historicamente, um estatuto de inferioridade estética com relação à literatura dirigida a adultos. Esse fenômeno pode ser percebido pelo próprio descaso com que a crítica literária tem tratado esse campo.

Como informa Sarland (2005, p. 35), até a década de sessenta do século XX, praticamente não existe crítica literária voltada para livros infantis, no contexto europeu e norte-americano, sendo que, possivelmente, essa informação possa ser generalizada com relação a muitos outros países, inclusive o Brasil. Por outro lado, a partir das décadas de 60 e 70 do século XX, essa situação muda radicalmente no contexto britânico e norte-americano, visto que uma série de críticos e demais intelectuais passam a realizar um trabalho bastante intenso de análises voltadas para questões relativas à representação e aos papéis de personagens em livros infantis.

Grande parte das análises de obras infantis produzidas principalmente no contexto anglo-saxão, a partir da década de 60, procura demonstrar como os livros de literatura destinados a crianças optam por representar certos grupos, excluindo outros tantos. Uma das primeiras constatações, nesse contexto, diz respeito ao fato de que a maior parte dos protagonistas dos livros analisados são meninos, brancos e de classe média, o que imediatamente fez emergir a denúncia de que tais obras estão fortemente atravessadas por preconceitos de classe, valores racistas e sexistas ${ }^{4}$.

\footnotetext{
${ }^{4}$ Para uma lista dos principais estudos e autores realizados nesse contexto, verificar o artigo de Charles Sarland, Critical tradition and ideological positioning. In: HUNT, Peter. Understanding children's literature. 2. ed. London \& New York: Routledge, 2005, p. 30-50.
} 
Além disso, esses estudos também procuraram denunciar o fato de que a maior parte dos livros infantis, até então, representava grupos minoritários de forma estereotipada. Meninos das classes de trabalhadores, por exemplo, geralmente eram representados demonstrando grande respeito em relação a seus pares mais ricos, ou então, eram representados como estúpidos. Personagens negras seguiam o mesmo percurso, sendo que, no que diz respeito a personagens femininas, geralmente eram elas encapsuladas dentro dos estereótipos de gênero dos modelos patriarcais.

Como reação a esse tipo de literatura e, ao mesmo tempo, como conseqüência dos trabalhos críticos realizados, em 1982 Bob Dixon elaborou uma das primeiras listas com obras marcadas por atitudes positivas em relação a questões de gênero, raça e classe social. A partir de então, segundo Sarland (2005, p. 34), esse tipo de lista tem se multiplicado, sendo que uma das principais conseqüências desse fenômeno tem sido a rápida proliferação de séries voltadas especificamente para a adolescência (que estava muito pouco representada nas obras analisadas), de um lado, e a emergência de vários autores que passaram a tratar de temáticas ligadas às diferenças, tais como Petronella Breinburg, Robert Leeson e Jan Needle, na Inglaterra, e Rosa Guy, Julius Lester, Louise Fitzhugh e Virginia Hamilton, nos Estados Unidos.

\section{Uma nova pedagogia: ensinando o politicamente correto}

No Brasil, em parte devido a essa tendência internacional no campo da crítica da literatura infantil e, em parte, devido às várias políticas de inclusão adotadas pelos governos federais e estaduais dos últimos anos, percebe-se uma nítida proliferação de obras destinadas ao público infanto-juvenil cuja principal temática está diretamente ligada à questão da diferença, com a presença de temas como a velhice, a infância pobre, vários tipos de deficiência física e mental, questões de raça e de gênero, entre outros.

Se, de um lado, nesse contexto, ocorre uma inversão quanto aos protagonistas das histórias - que deixam de ser apenas meninos, saudáveis, brancos e de classe média para se tornarem negros, índios, velhos, meninas, crianças pobres, deficientes etc. - de outro lado, a grande maioria dessas narrativas ainda é tributária de uma tradição histórica do campo da literatura infantil, a saber, seu caráter predominantemente 
moralizador e pedagogizante. Se, nos séculos XVIII, XIX e primeiras décadas do século $\mathrm{XX}$, a literatura infantil servia principalmente para ensinar regras de "bons costumes e comportamentos", civismo, religiosidade, além da própria leitura e escrita, atualmente, numa inversão surpreendente, ela parece estar ensinando, de modo francamente monológico, a política do multiculturalismo e do respeito às diferenças.

Já na década de 80, quando Dixon elaborou uma das primeiras listas de obras infantis "politicamente corretas", apontou para a necessidade de se avaliar, também, o aspecto estético das obras, embora ele mesmo tenha, para tanto, recorrido a critérios bastante conservadores, na medida em que se apoiou em um dos pensadores mais criticados no contexto das abordagens culturalistas contemporâneas, a saber, Leavis, que realizou uma diferenciação por demais dicotômica entre as assim chamadas alta cultura e baixa cultura.

Embora o presente artigo não tenha a pretensão de realizar uma análise literária ou estética de narrativas infantis - pois pretende focalizar a representação da personagem-professora na relação com a diferença -, é pertinente lembrar aqui que várias teorias contemporâneas de crítica literária, principalmente aquelas inspiradas em concepções semióticas e/ou textuais, elaboram critérios de valor estético baseados em conceitos como polissemia, plurissignificação, dialogismo, plurilingüismo, ambigüidade, priorizando, dessa maneira, a ampliação das possibilidades semânticas e interpretativas dos textos. ${ }^{5}$ Umberto Eco, por exemplo, chegou a afirmar que o prazer estético de uma leitura literária deriva justamente do jogo interpretativo realizado por parte do leitor, que passa a descobrir, a cada nova leitura, uma nova possibilidade de interpretação, devido ao caráter ambíguo e auto-reflexivo do signo estético. ${ }^{6}$

\section{Representações de professor/a: ensinando que somos todos iguais e que os diferentes também são capazes}

A literatura para crianças tem se valido, com muita freqüência, do espaço escolar como cenário para os desdobramentos do enredo e, de forma articulada, ela também está

\footnotetext{
${ }^{5}$ Sobre algumas das principais correntes semióticas de interpretação de textos estéticos e literários, verificar, entre outros, KIRCHOF, Edgar Roberto. Estética e semiótica: de Baumgarten e Kant a Umberto Eco. Porto Alegre: Edipucrs, 2003.

6 Entre outras obras, verificar principalmente ECO, Umberto. A estrutura ausente. São Paulo: Perspectiva, 1991, p. 68; ECO, Umberto. Tratado geral de semiótica. São Paulo: Perspectiva, 1997, p. 223.
} 
povoada de personagens típicas da instituição escolar. Considerando-se a identificação, no mundo ocidental, da representação da criança com a representação do aluno e, também, a reiteração do entendimento de que "escola é o lugar adequado para crianças", tal freqüência seria esperada, na medida em que os autores de obras infantis estariam explorando cenários, atividades, ritos e personagens que já fariam parte do repertório interpretativo de seus leitores.

Dentro desse quadro, a professora - e, com menos freqüência, o professor - tem sido retratada de diversas formas: maternal, boazinha, carinhosa, magnânima; irritada, gritona, histérica, autoritária; enclausurada dentro de um saber escolar específico etc ${ }^{7}$. A essas representações, mais disseminadas, acrescente-se - pelo menos no âmbito brasileiro - a imagem da professora construtivista, freireana ${ }^{8}$, democrática, que ouve os alunos e soluciona os conflitos através do diálogo. As análises propostas no presente artigo, por sua vez, vinculam-se à questão da proliferação da temática da diferença em livros recentes para crianças e serão realizadas à luz de duas principais perguntas: “Como são representadas professoras e professor em tais obras?" e "De que forma as representações da docência vinculam-se ao viés pedagógico e (in)formativo característico de grande número de livros escritos para crianças?”

Uma professora a quem o preconceito racial incomoda e que, de forma explícita, ensina - aos seus alunos ficcionais e aos seus leitores reais - que "somos todos iguais", encontra-se em "A Turma de Layla". De imediato, ressalta, nessa obra, um traço bastante comum na literatura para crianças que aborda a diferença (e, por que não admitir, também no discurso cotidiano de senso comum): a atribuição de uma (ou mais) virtude compensatória à personagem diferente ${ }^{9}$. A personagem negra, nesse contexto, não passa a merecer um tratamento igualitário em virtude de o racismo ser uma atitude

\footnotetext{
${ }^{7}$ A esse respeito, pode-se consultar os diversos estudos sobre representações de professor/a na literatura infantil constantes em SILVEIRA, Rosa Maria Hessel (org.) Professoras que as histórias nos contam. Rio de Janeiro: DP\&A, 2002, e FERNANDES, Célia Regina Delácio. Leitura, literatura infanto-juvenil e educação. Londrina: EDUEL, 2007.

${ }^{8}$ Ao usarmos o adjetivo freireano/a, referimo-nos à influência de Paulo Freire no discurso pedagógico brasileiro, com sua ênfase na consideração da voz e da experiência do aluno pelo professor e numa postura docente democrática dentro de sala de aula.

${ }^{9}$ SILVEIRA (2004, p. 181) observa a mesma tendência na análise de um livro infantil que, aludindo a uma menina surda e à sua dificuldade de entender a fala, é caracterizada pelo autor com o seguinte enunciado: "Mas ela é a melhor corredora da escola!".
} 
injusta e vexatória, mas, sim, porque se trata de uma menina inteligente, comunicativa, "lindíssima", que escreve poemas, é uma grande leitora (e de autores consagrados), é inocente e solidária. Como se percebe, "A Turma de Layla" é um livro decidida e assumidamente pedagógico, e isso se pode verificar pelo fato de que a autora dedica as sete primeiras páginas - do total de 15 da obra - a descrever o que seria uma pedagogia ideal para crianças em fase de alfabetização, pedagogia essa capitaneada pela "professora adorável":

$\mathrm{Na}$ verdade, as crianças aprendiam brincando e adoravam a professora, que diariamente viajava com seus alunos pelo maravilhoso mundo das letras. Para Layla, o mundo das letras era encantado. Às segundas-feiras, a professora iniciava a viagem partindo do alfabeto e indo à Estação Poesia. Ali então ela conheceu pessoas incríveis, que escreviam poemas adoráveis.

De estação em estação (à da Poesia, sucedem a dos Contos e Histórias Infantis, a da Música, a do Folclore e das Lendas e Parlendas, a do Cinema), tudo corre às mil maravilhas na sala da professora Marina, até o dia em que chega uma nova aluna, Valquíria, "transferida de uma cidade do interior". Configura-se, desse modo, o conflito racial na narrativa, que, inicialmente, gira em torno do repúdio de Layla por parte de Valquíria. Quando a professora, durante uma aula de Educação Física, solicita que as crianças se dêem as mãos, Valquíria nega-se a pegar a mão de Layla, ensejando a primeira manifestação da professora: “- Por favor, Valquíria, dê a mão para Layla! Cor não pega, não tenha medo!".

A partir desse momento, a professora assume o papel pedagógico de "trabalhar o problema". Primeiro, esclarece, à nova aluna, que "na sua turma todas as crianças são amigas, que uma ajuda a outra no grupo e que ela estimulava que seus alunos vivenciassem em sala de aula um clima de fraternidade"; em seguida, passa a trabalhar "as noções de igualdade e de diferença étnica", a partir do Art. $2^{\circ}$ da Declaração Universal dos Direitos Humanos. O conflito é intensificado, contudo, quando o pai da menina preconceituosa - ele também apresentado sem meias tintas -, adentra a sala de aula argumentando que "sua filha não senta ao lado de uma macaca". A professora, que, além de competente e amorosa, tem sangue frio, uma vasta cultura legislativa e está integralmente imbuída de seu papel civilizatório, responde com o seguinte discurso: 
- Esta menina tem nome, chama-se Layla. Como todos nós, ela também descende do "homo sapiens". O senhor tem alguma dúvida sobre isso? Já ouviu falar na Declaração Universal dos Direitos Humanos? Na Constituição Cidadã de 1988? Ou no Estatuto da Criança e do Adolescente (ECA)? Na Lei Cão? Na Lei Paim? Estas leis proíbem qualquer discriminação, sendo o racismo classificado como crime. (...) Lamento o que aconteceu e exijo que o senhor reconsidere o que falou sobre Layla, pois serei obrigada a tomar sérias providências e levar este caso à direção da escola e às autoridades competentes.

Frente à performance da professora, o pai de Valquíria ficou constrangido, desculpou-se imediatamente e "agarrou Layla ao colo, abraçou-a e beijou-lhe o rosto", pedindo perdão à menina negra. Essa cena, contudo, não constitui ainda o desfecho da história, pois Dona Marina, a professora, após resolver o conflito com o pai de Valquíria, retomou a aula e "permitiu que os alunos se expressassem com relação ao que acontecera na sala". E, para que não restassem dúvidas quanto à lição aprendida tanto para os personagens alunos, quanto para os leitores do livro - a professora solicita às crianças que recortem peixinhos em papéis de diferentes cores e os colem num cartaz representando o aquário. Por fim, enuncia sua lição final, "para concluir”, com a qual encerra o texto escrito:

- Muito bem! Assim também é nossa turma. Todos nós somos seres humanos, com etnias diferentes, cores diferentes, mas todos possuidores de dignidade, isto é, de valor.

No conjunto dos livros aqui analisados, "A Turma de Layla" é um caso extremo no que tange à representação da professora que explicitamente ensina como não devemos ser preconceituosos, a partir de explicações biológicas e alegações jurídicas. Observe-se, ainda, que o livro assimila progressivamente a voz da narradora onisciente à voz da personagem-professora, transferindo a esta o poder de explicar o sentido "correto" dos fatos.

Ainda que não tenhamos encontrado, no conjunto de obras sob análise, outro título em que o apelo pedagógico e moralizador seja tão direto, é preciso registrar a presença da "professora exemplar" atuando junto a seus alunos também em outros livros. Em "Não tem dois iguais", por exemplo, cujo foco narrativo está centrado em uma narradora-criança, já de início encontra-se uma referência à mestra e à sua função de explicar a diversidade: 
Meu nome é Carol e vou mostrar uma coisa bem bonita pra você. Bom, antes vou apresentar meus amigos aqui da escola.

$\mathrm{Na}$ minha turma tem dez crianças. A Andréa, nossa professora, diz que a gente parece os dedos das mãos: um diferente do outro.

Com o foco narrativo centrado sobre o ponto de vista da menina-narradora, as características apontadas nos colegas situam-se, inicialmente, no plano da aparência pessoal e do comportamento: tamanho, tipos de cabelo, temperamento, sendo que diferenças estigmatizáveis são colocadas em segundo plano. No entanto, essa perspectiva muda quando Carol passa a contar a história de sua amizade com Renato, um menino negro. É interessante observar que a negritude do personagem, inicialmente, é mostrada apenas na ilustração visual e não no texto verbal, onde apenas se narra a antipatia mútua entre as personagens:

Hoje, a Andréa formou duplas na hora de jogar e eu caí com o Renato. Fiz cara feia e ele fez uma careta mais feia ainda para mim.

Registre-se que a professora, a partir de sua apresentação, será sempre chamada de Andréa - sem qualquer epíteto (professora, tia, dona) - pela narradora-criança, o que já aponta para uma representação de docente amiga, afetiva, avessa a hierarquias. Essa tendência se confirma, na narrativa, pela representação icônica, na ilustração, de uma jovem de saia curta, cabelos presos com uma faixa juvenil, que se senta no chão junto aos alunos. Essa professora intervém na antipatia mútua dos dois alunos, adotando uma estratégia muito ao gosto das pedagogias ativas e democráticas: todos formam uma roda, sentam-se e conversam. "A gente sempre faz assim quando tem coisa séria para resolver", diz a narradora-criança.

Frente à implicância recíproca dos dois alunos - “(...) ele me chamou de branquela, cara de tigela. / - E você falou que eu era preto que nem pneu! - ele gritou" a professora "falou, brava": “- Vamos parar com isso já! O jeito que as pessoas são por fora não tem importância. O que vale é como elas são por dentro." Na seqüência, há uma demonstração, através de perguntas estratégicas feitas pela professora, de que todos os dez alunos são, de alguma maneira, diferentes, sendo que a diferença não faz com que qualquer um deles seja depreciado pelos colegas. A última afirmação do conclave, à guisa de conclusão, é colocada na boca de um pequeno aluno, o Cauã: “- Ia ser bem chato se a gente fosse tudo igual." 
Além de promotoras da igualdade e mestras do respeito às diferenças, as personagens professoras também auxiliam alunos em dificuldades (e, mesmo, seus pais) a perceberem o que os torna diferentes, bem como, eventualmente, a melhor forma de conviver e tirar proveito da diferença encontrada. "Quatro olhos", um livro com pouco texto verbal, enquadra-se no grupo de obras em que a professora é apenas a personagem que desconfia de que a causa das trapalhadas da menina (personagem sem nome) possa ser um problema de visão: "A professora chamou os pais da menina e aconselhou-os que a levassem ao médico". Diagnosticada a deficiência visual, a menina passa a usar óculos e a enxergar melhor os ambientes, mas acaba por receber o apelido de "Quatroolhos", o que, entretanto, não a intimida. Afinal, dentro da lógica da compensação segundo a qual a diferença é compensada através de alguma característica positiva freqüente nos enredos, a menina "ficou com o apelido de Quatro-olhos, mas se tornou uma das melhores alunas da escola e ninguém a pegava na queimada".

Com texto verbal mais extenso e maior número de páginas, a obra "A Formigadinha" apresenta um texto escrito em quadras a respeito de uma formiguinha irrequieta - a Formigadinha do título. A narrativa inicia com a caracterização de uma escola convencional à qual a protagonista não se adapta. Não falta, a essa escola, a figura da professora irritada, imagem bastante freqüente em outros livros de literatura infanto-juvenil. Por outro lado, foi essa mesma professora autoritária, embora "bem treinada", que "Chamou toda a família/ Porque estava preocupada. // Foi logo dizendo pra mãe/ Levar sua filha ao doutor/ Porque parecia que Dinha/ Era movida a motor."

Essa representação alinha-se a um quadro bastante contemporâneo de nossa sociedade ocidental, no qual as dificuldades das crianças são enquadradas em síndromes específicas. Através do saber médico, a personagem Formigadinha é diagnosticada como hiperativa, com déficit de atenção e com dislexia. Continuando na mesma escola, ela acaba por ser reprovada, e a solução virá através da sugestão da vovó Formidável: Formigadinha deve ser matriculada em uma escola progressista: a "Formiga Viva". É lá que a protagonista hiperativa desabrochará, em um contexto onde abundam as professoras "Tias Formigas" e os professores "Tios Formigos". O desfecho ocorre quando, ao final do ano, Formigadinha recebe um presente e um abraço da professora, convenientemente apresentado na ilustração, sendo que a "moral" desse desfecho poderia ser traduzida da seguinte forma: embora a personagem seja marcada por uma 
diferença, consegue superar seu "problema" porque é bem acolhida numa escola inspirada por todos os parâmetros do ideário pedagógico vigente, a saber, uma escola que privilegia a atividade, a diversificação de ritmos e tarefas de aprendizagem, a proposição de atividades prazerosas, as saídas de campo, entre outros.

Já em "O giro da bailarina", a narradora apresenta-se com nome e idade, dizendo-se emocionada por ter feito sua primeira apresentação de balé. Recorda, a seguir, a primeira vez em que lhe foi apresentada, na escola, a professora de dança:

Logo ergui meus braços para cima e me senti como uma bailarina. Minha professora sorriu.

Preparamo-nos então para a nossa primeira aula.

Ficamos amigas naquele momento.

Sem precisar dizer nada, somente pela ternura de nossos olhares enquanto dançávamos.

Efetivamente, o caráter excepcional da ação da professora de dança decorre do fato de a protagonista - e isso o leitor descobrirá, através do texto verbal e imagético, apenas na página 18 - ser uma cadeirante. Todo o livro se encaminha para uma narrativa de superação e felicidade, já que a narradora-protagonista consegue fazer algo que não se esperaria de uma menina com deficiência motora; em especial, algo ligado à arte da dança, cuja leveza é sugerida metaforicamente, na narrativa, também pela figura dos cisnes.

O professor masculino, menos freqüente nas representações da literatura infantil, está presente na singela obra "Nem todas as girafas são iguais". O livro, que não por acaso pertence a uma coleção intitulada Ciranda das diferenças, traz a história de animais antropomorfizados, apresentando, como protagonista, uma girafa nomeada Tina, cuja "diferença" consiste justamente em não possuir a característica diferencial que confere o exotismo da espécie aos nossos olhos ocidentais. Ou seja, Tina é baixinha. O tom pedagógico do texto é perceptível já na lição informativa da página que o abre: "As girafas são conhecidas por serem os animais mais altos que existem e podem chegar a medir até nove metros de altura. A girafa tem um pescoço bem longo, o que lhe possibilita o alcance dos alimentos que ficam nas árvores".

O caráter pedagógico dessa obra, contudo, não se restringe a informações de cunho biológico. A narrativa segue um esquema comum a outras histórias sobre diferenças para crianças (de certa forma, similar aos livros "A turma de Layla" e "Não tem dois iguais"): um narrador onisciente apresenta a personagem diferente (no caso, a 
girafinha que não crescia como as outras), descreve seu sofrimento devido à rejeição social de seus pares, em especial as zombarias de que é vítima (e aí, os apelidos desempenham um importante papel), enfatiza a sua exclusão das atividades para as quais a diferença é um empecilho, sendo que, eventualmente, também são relatados esforços para a busca da normalização (no caso, os esforços mal sucedidos da girafinha para crescer).

Surge, então, uma ocasião especial em que a personagem diferente poderá ser útil - no caso, um torneio de basquete e a falta de um técnico para o time das girafinhas. Nesse ponto, entra em cena um personagem clarividente, que sugere o aproveitamento da personagem: trata-se do professor de Educação Física, Caco, que, acamado com catapora (para não chocar as crianças, o melhor é apresentar uma doença típica da infância ...), não pode treinar o time, mas sabe que Tina conhece bem as regras e sugere seu nome como treinadora. Ainda dentro de um esquema narrativo bastante típico, a personagem diferente encontra algumas dificuldades (o time estava perdendo a última partida!), mas, graças à sua tenacidade e dedicação, vence o desafio (no exemplo, o torneio). Lê-se, então, o fecho da história: “A equipe Girassol foi a campeã do torneio e Tina descobriu que era uma ótima treinadora de basquete, mesmo sendo a girafa mais baixinha que alguém já conheceu."

\section{Representações de professor/a: corrigir a diferença ou sair de cena?}

Ainda que tenha sido dominante, no conjunto de livros analisados, a representação de professores/as como pedagogos/as do tratamento igualitário entre os diferentes, de um lado, e como incentivadores da potencialidade dos mesmos, de outro lado, em algumas obras a personagem do/a professor/a se desvia desse papel, o que pode ser exemplificado, entre outros, através de dois livros que também lançam mão de figuras de animais.

Em "Tico - o coelhinho das orelhas caídas", pequena obra repleta de clichês textuais (veja-se a freqüência de diminutivos) e imagéticos, introduz-se a história de "um casal de coelhinhos" que tinha "três filhotinhos muito espertos: Taco, Teco e Tico" , até que um dia, "olhando-se no espelho, Tico achou suas orelhas feias e caídas". Preocupada, a Mamãe Coelha chama a Coruja, apresentada como a "sabichona do lugar", que pode ser interpretada como uma professora, haja vista a simbologia 
tradicional da coruja e o fato de ser ela representada portando um livro. Pois bem, o que fez a Coruja sábia? "Colocou um suporte nas orelhas de Tico e disse: - Espere alguns dias e terá uma grande surpresa." Ao final do prazo, a mãe desamarra as orelhas de Tico, e ele percebe que suas orelhinhas (enfim, a diferença que o fazia entristecer) estão em pé. Corrigida a deficiência-diferença pela ação providencial da coruja-mestra-sábia, cabe a Tico sair "dando pulos de alegria, mostrando a todos as suas orelhinhas em pé".

Já em "Igor, o passarinho que não sabia cantar", estamos frente a uma história que foge bastante aos esquemas tradicionais tanto em relação ao tratamento da diferença, quanto em relação aos clichês imagéticos e narrativos. Chegada a primavera, Igor, um passarinho, estava ansioso para cantar pela primeira vez e tenta fazê-lo, participando do Coral do Amanhecer. O resultado é desastroso - todos os demais passarinhos reclamam da desafinação de Igor, que, desapontado, procura um aperfeiçoamento solitário, mas fracassa. Decide, então, tomar umas aulas de canto (corrigir sua diferença, digamos):

Então procurou dona Gansa, que era uma famosa professora de canto. "Deixe comigo", disse dona Gansa. "Não se preocupe. Cantar é fácil. Qualquer um é capaz."

Mas Dona Gansa, apesar dos esforços, desiste: "Igor", disse ela com a voz trêmula, "eu fiz o que pude... Sinto muito, mas fracassei." Diferente da sábia coruja que amarrou as orelhas de Tico, no livro anterior, e as colocou no lugar com sucesso, aqui, a professora Gansa sai de cena a fim de que Igor busque, ele próprio, uma solução para sua desafinação. Num final aberto e, conseqüentemente, polissêmico, Igor se isola dos outros pássaros, constrói um ninho e se motiva a cantar, certificando-se de que ninguém o ouvirá. A sensação de felicidade e liberdade o inunda, quando, então, um Dodó (possivelmente uma referência à ave extinta nas Ilhas Maurício) se acorda, maravilhado com o canto de Ígor, e realizam, então, um dueto, "enchendo o céu com uma linda canção". Teria Igor afinado seu canto? Ou ambos - animais que, de alguma maneira, foram rejeitados - constroem uma "nova afinação"? A criativa ilustração, com formas coloridas esvoaçantes pelo céu, permite várias leituras... mas, sem dúvida, a fonte para a superação da diferença não veio do ensinamento ou do exemplo docente, o que permite afirmar que esse livro escapa aos estereótipos e clichês predominantes na maior parte dos demais livros analisados. 
Em "Juntos somos ótimos", a ação se desenvolve numa sala de aula "inclusiva', na qual convivem várias diferenças; na trama, que se constrói com episódios e diálogos de sala de aula, são protagonistas, entre outros, Bianca, a menina cadeirante, e Max, o menino com síndrome de Down. As professoras são referidas pelo nome, como as demais personagens, e atuam dentro da expectativa cultural de uma conduta docente: ambas se aborrecem com o atraso de Max; a professora de Inglês ensina palavras na lousa e pede silêncio quando Max começa, subitamente, a dançar na sala de aula. Em certa passagem, a professora Sônia "tenta separar a briga de Bernardo e Fábio". No meio da trama, a mesma professora faz a sua intervenção mais longa sobre a questão da diferença, admoestando Bernardo:

\begin{abstract}
- Parem de se comparar uns com os outros. Pode até ser que um de vocês seja melhor que o outro em alguma coisa. Ninguém pode fazer tudo igualmente bem. O importante é que cada um tente dar o seu melhor. Isso vale tanto para o Max quanto para o Bernardo.
\end{abstract}

Entretanto, não é essa admoestação que surtirá o efeito de pacificar as rusgas entre os alunos, uma vez que um deles está inconformado com as perturbações que Max traz ao andamento da aula. É através de vivas disputas entre meninos e meninas e das inesperadas performances de Max que se chega ao desfecho da trama, em que uma colega, Sabrina, exprime sua interpretação de um desenho em que Max havia representado toda a classe: “- O Max faz parte do nosso grupo! (...) Ele é um excelente pintor de pensamentos!"

Por fim, também o livro "Ceci tem pipi” foge aos clichês encontrados em vários dos demais livros analisados, pois não apresenta o intento de normalização do diferente por parte de um adulto, tampouco a intervenção e as lições de uma professora ou professor sobre a conveniência do convívio respeitoso. Obra bastante original, com imagens que fogem ao caráter angelical, freqüente em ilustrações de livros para crianças, "Ceci tem pipi" focaliza a diferenciação de gênero e a perplexidade do protagonista Max - um menino que dividia o mundo entre o pessoal "Com-pipi” e o pessoal "Sem-pipi" -, quando conhece a nova colega Ceci. Ela é a personagem desequilibradora. Diferente das outras "Sem-pipi” que Max conhecia, Ceci é forte, desenha mamutes, joga futebol, tem bicicleta "de garoto", sobe em árvores e luta. É essa intrigante diferença de Ceci que constitui o nó da trama, para cuja solução a professora apenas aparece como coadjuvante: 
- Você desenha muito bem! exclama a professora, mostrando o desenho de Ceci.

No papel, não tem florzinha fofinha nenhuma! O que tem é um mamute enorme!

"Qual é a dessa garota?", Max fica pensando.

Se a professora não compartilha da classificação simplista de pessoas feita por Max - com suas formas de se comportar - também não o auxiliará diretamente a resolver o enigma. É o próprio menino que realiza uma longa e metódica investigação, a partir da qual descobre que Ceci, além de não ter pipi, não é uma "Sem-pipi", mas uma "Com-perereca", como a própria menina se define. A partir de tal "descoberta", Max conclui que "não tem nada faltando nas meninas!" e, enfim, diríamos, ressignifica as diferenças de gênero. Nesse caso, a "aprendizagem" do menino não é mediada nem pela professora tampouco pelos demais adultos que aparecem na trama - os pais -, mas se faz na própria experiência entre as crianças.

\section{Fechando as análises}

A partir do breve percurso feito por dez diferentes obras para crianças publicadas recentemente por variadas editoras brasileiras, cremos que é possível apontar a articulação entre o antigo compromisso entre literatura e pedagogia, tributário da origem daquela e de sua conexão com uma imagem de infância a ser educada e formada, por um lado e, por outro, a "nova" temática da diferença e do respeito aos diferentes. Ou seja: se a abordagem da diferença constitui atualmente (ao menos, na grande maioria dos países ocidentais) um tema que deve ser trabalhado com crianças, nada parece decorrer de forma mais natural do que fazê-lo através da literatura infantil, freqüentemente vista como apenas um recurso pedagógico lúdico e prazeroso.

Em conseqüência de tal articulação, vimos que, em vários dos livros analisados, o tom é francamente pedagógico, sem qualquer preocupação estética maior. Nesse sentido, podemos nos valer de Shavit (2007, p.77), que, ao analisar o narrador de uma versão para crianças de um conto originalmente escrito para adultos, observa:

Ele [o narrador autorizado] nunca deixa os acontecimentos por explicar para vir a explicá-los mais tarde. Quase tudo é explicado, e em geral em termos inequívocos. Além disso, o narrador coloca-se sempre em posição de julgar corretamente o que quer que seja dito". 
As lições explícitas sobre a diferença e os diferentes pululam nas páginas de vários livros, em que a verossimilhança e a literariedade são sacrificadas no altar dos ideais educativos imediatos. E, para dar maior peso às "lições", à personagem professora - tradicionalmente vista como formadora e informadora - é atribuído o papel de ensinar ou pela palavra (no caso de "A turma de Layla", p.ex.) ou pelo exemplo ("Nem todas as girafas são iguais", p.ex.). Em síntese, o predomínio, ainda, é de uma representação de uma professora redentora, que ensina o respeito e a convivência" ou usa de estratégias persuasivas para a turma acolher a diferença ou para o diferente se superar e achar "o seu lugar"..

Mas há rupturas neste modelo pedagogizante: a professora pode falhar no seu intento de normalizar ou de implantar a boa convivência, e a solução para as dificuldades deverá ser buscada pelo próprio diferente (é o caso de "Igor: o passarinho que não sabia cantar", p.ex.). Ou, ainda, embora presente, a professora é uma simples coadjuvante e o desfecho do conflito é buscado pelos protagonistas crianças, como em "Ceci tem pipi" e "Juntos somos ótimos".

Registre-se, ainda, que, em alguns dos livros analisados, encontram-se paratextos que explicam ou esclarecem dimensões da diferença focalizada ou do caso específico que serviu de mote para a escrita ficcional. Tal é o caso da lição sobre "Nanismo" (em "Nem todas as girafas são iguais"), do texto sobre a menina dançarina tetraplégica (em "O giro da bailarina"), do Glossário que esclarece hiperativa, déficit de atenção, dislexia (em "A Formigadinha") e dos textos explicativos sobre $O$ que é a síndrome de Down, O que é uma escola inclusiva, O que é normal e Síndrome de Down na escola (em "Juntos somos ótimos"). Para Colomer (2007, p. 87), este é um subterfúgio para evitar prejuízos à literariedade do texto para crianças:

Outro recurso (...) é "colocar-se ao lado", e assim acrescentar comentários diretos do adulto através de prólogos ou apêndices. Ou seja, dá-se prioridade à criação literária sobre a preocupação educativa durante a elaboração da obra, mas, ao mesmo tempo, os autores ou editores não renunciaram ao discurso educativo explícito; simplesmente o prenderam nesses textos circundantes.

Em menor número de casos, a $4^{\mathrm{a}}$ capa é o espaço em que o editor evidencia o endereçamento do livro ao leitor adulto - professor/a ou pai/mãe - , um dos pólos da dupla destinação do livro infantil ${ }^{10}$. Afirma-se, então, que a coleção foi "Criada sob

\footnotetext{
${ }^{10}$ Para uma interessante discussão sobre a tensão do duplo destinatário da literatura infantil e juvenil, ver
} 
orientação de educadores e inspirada em situações comuns no dia-a-dia" e "facilita a conversa entre os adultos e os pequenos" ou que se trata de "uma história sensível que mostra claramente como as crianças aprendem umas com as outras em uma escola inclusiva". Ou seja: explicita-se a não gratuidade da temática e da própria obra, a exemplaridade do enredo e, em certos casos, busca-se até o aval das vozes autorizadas para a abordagem (os "educadores"), quando não se lança mão do selo de autenticidade da inspiração em situações vividas (é o caso de "O giro da bailarina", por exemplo).

Nesse contexto de produção cultural no qual realizamos apenas esta breve incursão, muitas questões poderiam ser ainda colocadas e discutidas; optamos, entretanto, por encerrar nossas reflexões com apenas uma delas. Afinal, até que ponto e sob quais formas a polissemia, a plurissignificação, a ambigüidade, a surpresa e, enfim, a literariedade podem ser compatibilizadas com uma abordagem da temática da diferença nas narrativas para crianças?

\section{Referências}

BOURDIEU, Pierre. As regras da arte: gênese e estrutura do campo literário. São Paulo: Companhia das Letras, 1996.

COLOMER, Teresa. A formação do leitor literário. São Paulo: Global, 2003. Andar entre livros - a leitura literária na escola. São Paulo: Global, 2007.

ECO, Umberto. A estrutura ausente. São Paulo: Perspectiva, 1991. . Tratado geral de semiótica. São Paulo: Perspectiva, 1997.

FERNANDES, Célia Regina Delácio. Leitura, literatura infanto-juvenil e ilustração. Londrina: EDUEL, 2007.

KIRCHOF, Edgar Roberto. Estética e semiótica: de Baumgarten e Kant a Umberto Eco. Porto Alegre: Edipucrs, 2003.

LAJOLO, Marisa. Circulação e consumo do livro infantil brasileiro: um percurso marcado. In: KHÉDE, Sônia Salomão (org.). Literatura infanto-juvenil: um gênero polêmico. Porto Alegre: Mercado Aberto, 1986, p. 43-56.

SARLAND, Charles. Critical tradition and ideological positioning. In: HUNT, Peter. Understanding children's literature. 2. ed. London \& New York: Routledge, 2005, p. $30-50$.

COLOMER, Teresa. A formação do leitor literário. São Paulo: Global, 2003. p. 164 e ss. 
SHAVIT, Zohar. Poética da Literatura para crianças. Lisboa: Ed. Caminho, 2003.

SILVEIRA, Rosa Maria Hessel (org.) Professoras que as histórias nos contam. Rio de Janeiro: DP\&A, 2002.

. Contando histórias sobre surdos(as) e surdez. In: COSTA, Marisa Vorraber (org.) Estudos Culturais em educação: mídia, arquitetura, brinquedo, biologia, literatura, cinema... 2. ed. Porto Alegre: Ed. da UFRGS, 2004. p. 175-204.

ZILBERMAN, Regina. O lugar do leitor na produção e recepção da literatura infantil. In: KHÉDE, Sônia Salomão (org.). Literatura infanto-juvenil: um gênero polêmico. Porto Alegre: Mercado Aberto, 1986, p. 17-30. . A literatura infantil na escola. 10. ed. São Paulo: Global, 1998.

\section{Livros analisados}

CAMPOS, Carmen Lúcia. Não tem dois iguais. São Paulo: Escala Educacional, 2005.

GARCIA, Osório. Quatro-olhos. Juiz de Fora: Franco Editora, 2006.

HONORA, Márcia. Nem todas as girafas são iguais. São Paulo: Ciranda Cultural, 2008. HUAINNIG, Franz-Joseph; BALLHAUS, Verena. Juntos somos ótimos. São Paulo: Scipione, 2007.

KITAMURA, Satoshi. Igor: o passarinho que não sabia cantar. São Paulo: Companhia das Letrinhas, 2006.

LENAIN, Thierry. Ceci tem pipi? São Paulo: Companhia das Letrinhas, 2004.

LOPES, Keyla Ferrari. O giro da bailarina. São Paulo: Paulinas, 2006.

PINTO, Gerusa Rodrigues. Tico o coelhinho das orelhas caídas. Belo Horizonte: Editora Fapi, s/d.

RAMOS, Rossana. A formigadinha. São Paulo: Cortez, 2006.

RITA, Maria. A turma de Layla. Santa Maria: A Autora, 2005. 